\title{
BARRIERS TO DIRECTLY OBSERVED TREATMENT FOR MULTI DRUG RESISTANT TUBERCULOSIS PATIENTS IN NEPAL - QUALITATIVE STUDY
}

\author{
Bichha RP'1, Karki KB'1, Jha KK'1, Salhotra VS'1, Weerakoon AP'1 \\ ${ }^{1}$ SAARC Tuberculosis and HIVIAIDS Centre
}

\begin{abstract}
Introduction: To prevent the multi drug resistant tuberculosis (MDR-TB) is important to adhere long duration of drug regimen. There are many factors or barriers that are likely to affect adherence to the long treatment regimen.

Objectives: To find out the barriers for adherence to MDR -TB treatment.

Methods: The study was conducted as an institutional based qualitative study, using a convenient sampling technique. Data was collected from 50 current MDR-TB patients by trained field health workers using semi structured interviewer administered questionnaire in all regions in Nepal. Twenty five focus group discussions (FGD) were also conducted with MDR-TB patients, cured MDR-TB patients, DOTS Committee Members, health workers and close relatives of MDR-TB patients to supplement the findings.

Results: Out of 50 respondents 19 were females and 31 were males. Their age varied from 22 years to 61 years. Majority of patients had a previous history of irregular TB treatment. Forty out of fifty patients $(80 \%)$ were living in either rented houses or hostels (in Mid Western Region). Knowledge about TB and MDR-TB was satisfactory in majority of participants in both studies. Majority of participants were satisfied with facilities and services provided by MDR-TB clinics. There is a very little stigma associated with MDR-TB in Nepal. FGD revealed the onset of MDR-TB was attributed to causes such as smoking, alcohol abuse, poor nutrition, and contact with TB patients. Lack of money to go to health facility daily for treatment was reported as major barriers to adhere to MDR-TB treatment.
\end{abstract}

Conclusion: Financial constraints were the major barrier for these patients. To sustain proper MDRTB programme, Government of Nepal and other organization should provide social support to these patients.

Key words: MDR-TB, Barriers, Nepal

\section{INTRODUCTION}

Anti -TB drug resistance largely arises when patients with the disease are prescribed suboptimal regimen not conforming to international recommendations in terms of the combination, dosage and duration for which the drugs are prescribed, or when patients for a number of

\section{Correspondence:}

Dr. Ajith Weerakoon

Epidemiologist

SAARC TB \& HIVIAIDS Centre, Kathmandu, Nepal

Email: saarctb@mos.com.np reasons do not take their medicines as prescribed. Drug resistance that arises through genetic mutation contributes to a much lesser extent.

Multidrug -Resistant TB or MDR-TB refers to Mycobacterium tuberculosis isolates that are resistant to at least both isoniazid and rifampacin, the two most effective first line anti TB drugs. MDRTB can only be treated with second -line drug regimen comprising reserve or second-line drugs, which are much more expensive, have to be used for a longer duration, entail significantly higher side - effects and result in much poorer outcomes as compared to first-line regimen. 
Along with HIVIAIDS, MDR TB is the most important threat to TB control. Countries with a high MDR -TB prevalence generally have a history of poor TB control. The major barrier to MDR-TB treatment is the high cost of second -line drugs which are at least 300 times more expensive than first- line drugs based on Green Light Committee (GLC) prices and between 1000 - 3000 times more expensive when market prices are used. In Nepal these second line drugs are given to the patients free of charge. Additional barriers include extensive laboratory requirements to conduct culture and drug susceptibility testing (DST), severe adverse events associated with second-line drugs and fear of non response or development of resistance to second -line drugs. In addition, private practitioners and public providers not linked to the NTP diagnose and treat MDR-TB patients in many countries including China and India which account for $35 \%$ of the global TB case- load, and treatment practices often fail to meet acceptable standards. The misuse of second- line drugs could lead to the creation of TB strains resistant to all known antiTB drugs.

\section{MDR-TB problem in Nepal:}

In Nepal MDR-TB management services are available from all five Regions of the country.

In Nepal previous work has shown that MDR $-T B$ is a public health problem. Since 1996, surveillance of anti- tuberculosis drug resistance has been conducted with the co-operation of the World Health Organization, the National TB centre and GENETUP. The proportion of MDR-TB among new cases in Nepal, has fluctuated from a little over $1 \%$ to $3.6 \%$ in the surveys that have been conducted since 1996 making the trend difficult to interpret. In 2015 WHO estimates that there were 1500 (Cl: 950-2100) MDR-TB cases in Nepal. The proportion of new cases with multidrug-resistant TB (MDR-TB) was 2.2\% among new cases and $15.4 \%$ among retreatment cases based on survey carried out in 2011/12, and new surveillance on MDR-TB has not been done in recent years. In 2014/15, total of 379 MDR-TB and 71 XDR TB were enrolled for treatment. Treatment Success Rate (TSR) of MDR patients was $71 \%$, however the TSR of XDR is low at $33 \%$. Total of 22 deaths among MDR Cases and 3 deaths in XDR were reported in 2014/15. The drug resistant pattern in Nepal showed much higher levels of resistance to fluoroquinolones (36\%). Among the MDR patients, $8 \%$ further develop XDR.(1)

\section{Constraints and challenges in MDR-TB case management in Nepal:}

Lack of socio-economic support for patients and infection are key challenges foroptimal performance of MDR-TB management in Nepal. Lack of focal staff at central level is another key constraint. Also MDR -TB management programme is managed through existing staff within $\mathrm{PHC}$ who received no extra remuneration or incentives for the additional responsibility ${ }^{(1)}$.

\section{Magnitude of adherence and non-adherence:}

The gap between the medication prescribed by the health care provider and that taken by the patient is wide. Based on a number of rigorous reviews from the studies done in developed countries, it has been found that the adherence among patient suffering from chronic diseases only $50 \%$ on an average. The magnitude and impact of poor adherence in developing countries is assumed to be even higher. Hence, the impact of poor adherence grows as the burden of chronic diseases grows worldwide. Poor adherence is the primary reason for suboptimal clinical benefit(2). It causes medical and psychosocial complications of diseases reduce patients' quality of life, and wastes health care resources. Taken together, these direct consequences impair the ability of health care systems around the world to achieve population health goals. Adherence problems are observed in all situations where the self- administration of treatment is required, regardless of type of diseases, disease severity, and accessibility to health resources. Medication adherence can be surprisingly low even among inpatients when they are on self- administration programmes (3).

With regard to treatment non-adherence, several qualitative studies reported different factors associated to it; they are related to poor socioeconomic position of patients (4)., inadequate and poor health care delivery system ${ }^{(5)(6)}$, treatment related problems like dissatisfaction with the treatment due to medication side effects ${ }^{(7)}$ and patients related factors like lack of understanding of adherence( ${ }^{(8)}$, equating well being with cure ${ }^{(9)}$,etc.

These all above mentioned studies amply indicate that the perceptions, beliefs, experiences and knowledge of individual about chronic diseases like TB have important bearing in interpretation of symptoms, give those meanings, decide with whom 
to consult, and how long remain in the treatment. We are not aware of any study from SAARC region dealing with all these aspects related to MDR-TB and its treatment. Hence the aim of this study was to achieve the following objectives.

\section{Objectives:}

\section{General Objectives:}

To find out factors, conditions and barriers relating to adherence to MDR-TB treatment in Nepal and to find out knowledge, perceptions, attitudes, practices, beliefs, and experiences of service users and service providers about MDR TB and its management.

Specific Objectives:

1. To find out factors affecting patients' adherence to MDR -TB

2. To find out service users and service providers knowledge, perceptions, attitudes, practices, and beliefs, about MDR TB and its management.

\section{METHODOLOGY}

\section{Study settings:}

Selected institutions in Nepal where MDR-TB treatment were carried out was the focal point for the study.

\section{Study design:}

This study used qualitative research methods to address the research objectives. Qualitative research is defined as any kind of research that produces findings not arrived at by means of statistical procedure or other means of quantification. The application of qualitative methods allows the researcher to study selected issues in depth and detail (10). Following qualitative methods were use for this study.

1. Focus Group Discussion

2. Semi structured interviews

\section{Sample size and sampling:}

Qualitative studies generally focus in depth on a relatively small number of cases selected purposefully. There are no hard and fast rules for sample size in qualitative research. As Hudelson points out (1994)" The sample size will depend on the purpose of the research., the specific research questions to be addressed, what will be useful, what will have credibility, and what can be done with available time and resources ${ }^{(11) . "}$

In qualitative sampling, the selection of respondents continues until the point of redundancy (saturation). When new interviews no longer yield new information and all potential sources of variation have been adequately explored, sampling may stop ${ }^{122}$. Considering all these factors, for semi structured interviews, fifty (50) MDR TB patients were enrolled from the five MDR-TB treatment centres in Nepal.

(1) Focus group discussions (FGD)s: Series of five FGDs were carried out in each region of Nepal with the following groups.

1. MDR patients

2. Close relatives /Friends of MDR patients

3. Health workers who are working in MDR-TB treatment clinics

4. Cured TB patients

5. Members of DOTS committee.

On an average seven to 10 individuals participated in the one to one and half hour sessions .A trained health worker conducted these FGDs using a set questionnaire. The FGD with the participants were held during the day in an open space, where the participants and moderator of the FGD sat together in a circle. During the FGD with MDR-TB patients, others were kept out of the vicinity. Staff of the National TB programme was asked not to be present so that participants would feel free to voice their honest perception about barriers faced by MDR-TB patients.

\section{Semi structured interviews:}

Semi- structured qualitative interviews were conducted with 50 MDR-TB patients, who were taking the second line Anti TB drugs. Interviews were conducted, with the help of an interview guide in Nepali language as it is the vernacular language of the informants. During interview every effort was taken to maintain privacy of the patient. Children (age below 15 years) were excluded from the study

\section{Ethical Issues:}

Permission from relevant authorities Director NTC, Regional Directors, District TB and Leprosy Control Officers etc) was taken before commencement of the study. 
Verbal informed consent was obtained from patients before starting interviews. Confidentiality of the status of patients was maintained at all times.

\section{Analysis of data:}

Focus Group Discussion: Analysis of data was done using following steps

(a) Data immersion - reading and rereading each set of notes or transcripts until familiar with the content.

(b) Data coding

(c) Data display

(d) Data reduction

(e) Interpretation and conclusion drawing

Semi structured questionnaire was analysed using SPSS software.

Results:

Table 1: Distribution of MDR-TB cases by sex

\begin{tabular}{|c|c|c|}
\hline Male $(\%)$ & Female $(\%)$ & Total \\
\hline $31(62 \%)$ & $19(38 \%)$ & $50(100 \%)$ \\
\hline
\end{tabular}

Table 2: Distribution of MDR-TB cases by Age

\begin{tabular}{|l|c|c|}
\hline \multicolumn{1}{|c|}{ Age group (years) } & No & $\%$ \\
\hline $15-24$ & 03 & $06 \%$ \\
\hline $25-34$ & 21 & $42 \%$ \\
\hline $35-44$ & 15 & $30 \%$ \\
\hline $45-54$ & 07 & $14 \%$ \\
\hline $55-64$ & 04 & $08 \%$ \\
\hline Total & 50 & $100 \%$ \\
\hline
\end{tabular}

Minimum age $=22$ years Maximum age $=61$ years

\begin{tabular}{l|c|c|}
\hline \multicolumn{3}{|l|}{$\begin{array}{l}\text { Table 3: Distribution of MDR-TB cases by } \\
\text { status }\end{array}$} \\
\hline Marital status & No & $\%$ \\
\hline Married & 24 & $48 \%$ \\
\hline Unmarried & 21 & $44 \%$ \\
\hline Widower & 02 & $04 \%$ \\
\hline Divorce & 01 & $02 \%$ \\
\hline Separated & 01 & $02 \%$ \\
\hline Total & 50 & $100 \%$ \\
\hline
\end{tabular}

\begin{tabular}{|c|c|c|}
\hline Literate (\%) & Illiterate (\%) & Total \\
\hline 38 (76\%) & $12(24 \%)$ & $50(100 \%)$ \\
\hline
\end{tabular}

Table 4(a): Distribution of literate MDR-TB cases by educational status $(\mathrm{n}=38)$

\begin{tabular}{|l|c|c|}
\hline Educational status & No & $\%$ \\
\hline Primary & 25 & $65.8 \%$ \\
\hline Secondary & 11 & $28.9 \%$ \\
\hline Higher & 02 & $5.3 \%$ \\
\hline Total & 38 & $100.0 \%$ \\
\hline
\end{tabular}

Table 5: Distribution of MDR-TB cases by current place of living

\begin{tabular}{|l|c|c|}
\hline Place of living & No & $\%$ \\
\hline Own house & 07 & $14 \%$ \\
\hline Rented house/ leased & 32 & $64 \%$ \\
\hline Hostel & 08 & $16 \%$ \\
\hline Others & 03 & $06 \%$ \\
\hline Total & 50 & $100 \%$ \\
\hline
\end{tabular}

In the literate group educational status was divided into 3 groups as primary, secondary and higher education.

Table 6: Distribution of MDR-TB cases by current employment status

\begin{tabular}{|l|c|c|}
\hline Employed (\%) & Unemployed (\%) & Total \\
\hline $06(12 \%)$ & $44(88 \%)$ & $50(100 \%)$ \\
\hline
\end{tabular}

All current employed patients (6) worked as farmers.

\begin{tabular}{|c|c|c|}
\hline Monthly family income(NRs) & No & $\%$ \\
\hline Less than 3000 & 36 & $72 \%$ \\
\hline $3001-5000$ & 10 & $20 \%$ \\
\hline More than 5001 & 04 & $08 \%$ \\
\hline Total & 50 & $100 \%$ \\
\hline
\end{tabular}

\section{Knowledge of TB and MDR-TB}

There were five questions concerning about knowledge in terms of causes of tuberculosis, duration of treatment for both TB and MDR-TB, impact of irregular or defaulter treatment, curability and spread from one patients to another. 


\begin{tabular}{|l|c|c|c|}
\hline \multicolumn{4}{|l|}{$\begin{array}{l}\text { Table 8: Distribution of MDR-TB cases by } \\
\text { Knowledge of TB and MDR-TB }\end{array}$} \\
\hline $\begin{array}{l}\text { Variables to know } \\
\text { about Knowledge }\end{array}$ & Know (\%) & $\begin{array}{c}\text { Don't } \\
\text { know (\%) }\end{array}$ & Total \\
\hline Causes of TB & $20(40 \%)$ & $30(60 \%)$ & 50 \\
\hline Treatment duration & $45(90 \%)$ & $05(10 \%)$ & 50 \\
\hline $\begin{array}{l}\text { Impact of irregular } \\
\text { treatment }\end{array}$ & $41(82 \%)$ & $09(18 \%)$ & 50 \\
\hline Curability & $50(100 \%)$ & $00(0 \%)$ & 50 \\
\hline Mode of spread & $22(44 \%)$ & $28(56 \% 0$ & 50 \\
\hline
\end{tabular}

\section{Quality of services:}

Quality of services was assessed in terms of waiting time per visit, information given to the patients about TB and MDR-TB and its treatment and side effects, relationship between patients and health care providers to get high compliance of patients with treatment and facilities available at clinics.

\section{Waiting time:}

\begin{tabular}{|c|c|c|}
\hline Waiting time & No & $\%$ \\
\hline One to 2 hours & 46 & $92 \%$ \\
\hline More than 2 hours & 04 & $08 \%$ \\
\hline Total & 50 & $100 \%$ \\
\hline
\end{tabular}

Table 10: Given information by health workers about disease, treatment and side effects to the patients

\begin{tabular}{|l|c|c|}
\hline $\begin{array}{l}\text { Given information by health } \\
\text { workers }\end{array}$ & No & $\%$ \\
\hline Information given was sufficient & 47 & $94 \%$ \\
\hline $\begin{array}{l}\text { Information given was not } \\
\text { sufficient }\end{array}$ & 03 & $6 \%$ \\
\hline No information was given & 00 & 00 \\
\hline Total & 50 & $100 \%$ \\
\hline
\end{tabular}

Table 11: Relationship between patients and health service providers

\begin{tabular}{|l|c|c|}
\hline $\begin{array}{l}\text { Relationship between patients } \\
\text { and health service providers: }\end{array}$ & No & $\%$ \\
\hline Good relationship & 48 & $96 \%$ \\
\hline Poor relationship & 02 & $04 \%$ \\
\hline Total & 50 & $100 \%$ \\
\hline
\end{tabular}

\begin{tabular}{|c|c|c|c|c|c|}
\hline $\begin{array}{l}\text { Facilities } \\
\text { available at } \\
\text { the clinic }\end{array}$ & CR & ER & WR & MWR & FWR \\
\hline Sitting facilities & Yes & Yes & Yes & Yes & Yes \\
\hline Toilet facilities & Yes & Yes & Yes & Yes & Yes \\
\hline Drinking water & No & Yes & Yes & Yes & Yes \\
\hline $\begin{array}{l}\text { Maintained } \\
\text { confidentiality }\end{array}$ & Yes & Yes & Yes & Yes & Yes \\
\hline $\begin{array}{c}\text { Availability of } \\
\text { drugs }\end{array}$ & Yes & Yes & Yes & Yes & Yes \\
\hline $\begin{array}{c}\text { Clinic } \\
\text { arrangements }\end{array}$ & Good & Good & Good & Good & Good \\
\hline $\begin{array}{l}\text { Courtesy of } \\
\text { health worker }\end{array}$ & Good & Good & Good & Good & Good \\
\hline $\begin{array}{c}\text { Cleanliness of } \\
\text { the clinic }\end{array}$ & $\begin{array}{l}\text { Not } \\
\text { good }\end{array}$ & Good & $\begin{array}{c}\text { Not } \\
\text { good }\end{array}$ & Good & Good \\
\hline $\begin{array}{l}\text { Competence } \\
\text { of the Health } \\
\text { Worker }\end{array}$ & Good & Good & $\begin{array}{c}\text { Not } \\
\text { good }\end{array}$ & Good & Good \\
\hline
\end{tabular}

CR-Central Region

ER-Eastern Region

ER- Western Region

MWR-Mid Western Region

FWR-Far Western Region

\section{Accessibility of services:}

Accessibility of service was assessed by using 4 questions.

(a) Travelling time

(b) Travelling and other costs

(c) Mode of transportation

(d) Availability of services during public holidays and "Bandha" days

Table 13: Distribution of MDR-TB patients by travelling time to reach the clinic

\begin{tabular}{|l|c|c|}
\hline Travelling time & No & $\%$ \\
\hline Less than one hour & 43 & $86 \%$ \\
\hline More than one hour & 07 & $14 \%$ \\
\hline Total & 50 & $100 \%$ \\
\hline
\end{tabular}

Table 14: Distribution of MDR-TB patients by travelling and other cost per day to attend to the centre

\begin{tabular}{|l|c|c|}
\hline Travelling cost/per day & No & $\%$ \\
\hline Less than 100 NRs & 37 & $74 \%$ \\
\hline More than 100 NRs & 13 & $26 \%$ \\
\hline Total & 50 & $100 \%$ \\
\hline
\end{tabular}




\begin{tabular}{|l|c|c|}
\hline \multicolumn{3}{|l|}{$\begin{array}{l}\text { Table 15: Distribution of MDR-TB patients by } \\
\text { mode of transport to attend the centre }\end{array}$} \\
\hline Mode of transport & No & $\%$ \\
\hline By foot & 24 & $48 \%$ \\
\hline Bus & 11 & $22 \%$ \\
\hline Rickshow & 07 & $14 \%$ \\
\hline Tampo & 04 & $8 \%$ \\
\hline Bicycle & 04 & $8 \%$ \\
\hline Total & 50 & $100 \%$ \\
\hline
\end{tabular}

Majority (92\%) stated clinic was open during public holidays and Bandha days. Four patients stated clinic was closed on Saturdays but open on Bandha days.

\section{Drug side effects experienced by patients $(n=50)$}

\section{Table 16:Distribution of MDR-TB patients by side} effects of drugs

\begin{tabular}{|l|c|c|}
\hline Side effects of drugs & No & $\%$ \\
\hline Gastritis & $3 / 50$ & $6 \%$ \\
\hline Loss of appetite & $6 / 50$ & $12 \%$ \\
\hline Itching & $7 / 50$ & $14 \%$ \\
\hline Jaundice & $1 / 50$ & $2 \%$ \\
\hline Joint pain & $10 / 50$ & $20 \%$ \\
\hline Hearing disturbances & $1 / 50$ & $2 \%$ \\
\hline
\end{tabular}

Table 17: Barriers to attend the Clinic daily

\begin{tabular}{|l|c|c|c|c|c|}
\hline Barriers & CR & ER & WR & MWR & FWR \\
\hline $\begin{array}{l}\text { Environmental } \\
\text { obstacles }\end{array}$ & $2 / 10$ & $3 / 10$ & - & - & - \\
\hline $\begin{array}{l}\text { Financial } \\
\text { problems }\end{array}$ & - & $3 / 10$ & - & $1 / 10$ & $5 / 10$ \\
\hline $\begin{array}{l}\text { Family } \\
\text { problems }\end{array}$ & $1 / 10$ & - & - & $2 / 10$ & - \\
\hline $\begin{array}{l}\text { Other health } \\
\text { related } \\
\text { problems }\end{array}$ & $1 / 10$ & $4 / 10$ & - & $1 / 10$ & - \\
\hline
\end{tabular}

Out of 10 patients in the Far Western region, five $(50 \%)$ stated that they were not attend the clinic regularly due to the financial problem. This percentage in the Eastern and Mid Western region was $30 \%$ and $10 \%$ respectively. Two patients in the Central and 3 patients in the Eastern region had not attended clinic regularly due environmental obstacles. Four patients in the Eastern and one each in the Central and Mid Western region did not attend clinic regularly due to other health related problems.

\section{Major Finding of FGD:}

The participants (MDR-TB patients and their relatives) demonstrated a basic knowledge of the symptoms of TB, causes and spread of TB. Whereas Health workers, DOTS Committee members and cured TB patients had more in-depth knowledge. Most said they knew it was an infectious disease that caused coughing up blood sometimes along with weight loss and fever. Majority of the health workers and DOTS committee members in every FGD stated that do not have any fear to treat and care for TB patients. They know TB is a treatable disease.

Many participants agreed that men and economically poor people are more prone to be infected by TB.. The reasons for this might be that men moves more outside and habituated to smoke more than females. Most of the participants including health workers group mentioned that there is a strong relation between TB/ MDR-TB and poor nutrition. They further stated poor people cannot afford enough nutrition; hence they are more vulnerable to develop TB and MDR-TB.

Many participants in the MDR-TB group stated that they trust the government health workers more as compared to the traditional healers and private sector medical personnel. In answer to the question -why patients would feel more comfortable going to the government doctor?, the answer came up as they feel comfortable with the services given by them and they are assured about the medicine quality which is given by government health workers. Many MDR-TB patients and cured TB patients stated health workers are co operative and helpful. They feel health workers are part of their family and understand their problems. They are easy to communicate with and most of all, they feel confident that they will keep their health problem a secret.

Most people received their information about TB from, Television, Radio and print media. Some participants in the relatives of MDR-TB group learned about the disease from the patents and from the treatment centre. About half of the MDR-TB patients group had seen posters visual aids demonstrating symptoms or some kind of information about TB especially in and around treatment centre.

Majority of the MDR-TB patients and relatives of the MDR-TB patient pointed out that MDR-TB is a 'dangerous' illness. This result in loss of weight and weakness associated with inability to work. In 
consequence the patient leaves the job or reduces the routine activity.

Based on the FGDs with health workers, following areas were identified as those within which the health workers played key roles.

1. Patient focused activities such as evaluating patients prior to starting treatment, giving treatment, monitoring patients during treatment.

2. Health education activities

3. Coordination activities such as documenting important clinical and programmatic information, attend meetings workshops conducted by NTP etc.

The first response of HCWs in Nepal, when asked about how to address the problems of non adherence, they often stated that a tracing system needs to be initiated. The health workers spent most of the time in patient care activities and this was the most important part of their work. This attitude of health workers is encouraging as health workers are the primary persons responsible for educating patients and their family members about MDR-TB and its management. But majority of health workers stated that they need self protection equipments like face marks for protection against the disease.

During FGD, majority of participants agree that patients prefer to attend Central Region clinics, because they think clinics in the Central Region have more facilities than other regions. Majority of DOTS Committee members, cured TB patients suggested that health care workers should intensively supervise patients because they may discontinue treatment.

Cured TB patients, DOTS Committee members and health workers acknowledged that the use of unqualified private practitioners before government medical services was wide spread and this is the main reason for spread of MDR-TB in Nepal. Few MDR-TB patients stated that they had used traditional healers previously. Motivation for using traditional medicine varied but many patients claimed to have done so because of easy access, confidentiality, local availability and on the advice of others. All participants in the FGDs thought most MDR-TB patients could not afford the fares to attend treatment clinic, and felt women experience more problems due to lower income. Nearly half of the female MDR-TB patients interviewed stated that they would prefer a female health worker to deliver their treatment.

\section{Barriers to DOT for MDR-TB patients in the Central Region:}

(a) Financial Barriers:

Majority of participants in all FGDs agreed financial problems were most common barrier for patient's to adhere to long duration of treatment. Majority of MDR-TB patients were either staying in rented home or relative's home which is in close proximity to the clinic. Usually they spend 3000 5000 NRs per month for accommodation and other expenses. One patient said that, he has sold one of his parents land to get the money to pay the expenses. The general consensus was that a very small percentage of patients from study population had access to their own source of income. Many depend on the family members for their expenses. Some patients arranged this money from loans with high interest rates. Many patients, Health Workers/ DOTS Committee members/ relatives of patients indicated that financial aid would improve the system.

\section{(b) Stigma and discrimination in the society:}

The majority of MDR-TB patients said that in general they would inform their family members if they found they are having MDR-TB but they might be afraid to tell outsiders especially land lord. Some patients feared that they will not get accommodation if land lord know about their disease status. Hence, they have a tendency to hide the disease. In addition, most felt that, if unmarried female patients were exposed that they have the disease, they might experience difficulty to get married

\section{Major barriers to get DOT in Western Region:}

- Less cooperation from family, mostly for the female

- Long distance to treatment Centre from the house. Since there is no provision of lodging nearby the Centre.

- Financial constraints. Loss of employment and earning.

\section{Barriers to DOT for MDR-TB patients in the Far Western Region}

- Lack of financial support for the treatment. Though the medicine is free of cost, most of the participants revealed that the patients loose their job because of the disease. 
- Lack of adequate family and social support.

- Side effects of the anti TB drugs (weakness, psychological stress, depression, irritation, anxiety, gastritis, headache, loss of memory power, joint pain, itching and numbness of feet).

\section{Barriers to DOT for MDR-TB patients in the Eastern Region}

- Long distance to travel

- Side effects of the drugs

- Financial problems

- Stigma and discrimination from the community

\section{Barriers to DOT for MDR-TB patients in the Mid Region}

\section{- $\quad$ Long distance to travel}

- Side effects of the drugs

- Financial problems

- Stigma and discrimination from the community

\section{DISCUSSION}

Although the aetiology of tuberculosis can be traced to Mycobacterium, it has frequently been observed that there is a predisposition for the disease among populations with low socio -economic status. Relevant observations can be made on a global scale, where the highest burden from the disease is observed in developing countries, as well as within countries, where the disease is largely confined to sub populations within various characteristics of socio-economic deprivation such as homelessness or absolute poverty (13)(14)(15). Insufficient patients compliance to anti TB drugs has repeatedly been proposed as one of the main causes of the ineffectiveness of many tuberculosis control programs, and a variety of contributing socio-economic factors have been described (16) (17)(18). Non adherence to treatment often results from inadequate knowledge or understanding of the disease and its treatment, psycho-social and economic factors, complexity of treatment, occurrence of side effect, and insufficient patient/ caregiver communication ${ }^{(19)(20)}$.

\section{Socio-economic factors:}

In the present study the youngest age of MDRTB patients was 22 years and oldest was 61 years. Forty eight \%of respondents belonged to the young age group (15-34 years) and 92
$\%$ economically productive age group (15- 54 years).This is in line with national level statistics in Nepal where largest number and proportion of MDR-TB belongs to 15-54 age group with almost half of the registered patients in age group 15-34 years. It has direct impact on the family, society and national economy. This study showed that the $88 \%$ of MDR-TB patients were unemployed and $92 \%$ respondents had average monthly income less than 5000 NRs (US \$50). Concerning the sex, $62 \%$ of MDR-TB patients were male and $38 \%$ were females. This trend corresponds with ratio of male to female registered under DOTS programme in Nepal. Statistics show that globally when males and females are provided with equal access to health care services, there are more female TB patients, and in developing countries like Nepal that most of the TB patients are male. According to one study conducted by Smith in Nepal, women and daughters are the last to seek medical help in Nepal's male dominated society. Women do not open up with problems. Study also stated that, even in Kathmandu there are still many families who take sick sons for medical treatment, while keeping their sick daughters behind home. Usually women with their nurturing roles, give less priority to their own health problems. The first indicator of pulmonary TB, the cough is not seen as a problem by rural women in hilly Nepal. According to the Smith (21) " the women sit by the fire every day, as many women smoke, so they expect to cough and even they do go to the health clinic they may not report their cough as a symptom ". The study showed that the 44 out of 50 MDR-TB patients were currently unemployed. Most of the patients were in employment had stopped working due to their ill health. This shows the MDR-TB population is mainly the work force and thus the morbidity and mortality that TB population suffer will affect the economy, as well as the cost to the health services in the country.

In this study $44 \%$ were never married. Two percent of the respondents reported separation from their spouse. The divorce rate of study population was very low $(2 \%)$. This may be due to sociocultural practices prevailing in the SAARC region especially Nepal where divorce is unacceptable by the society. The majority of MDR-TB patients had received either no or primary education. Few $5.6 \%$ made it to higher education. Many studies conducted in the past revealed that low education level was significant predictor for non-adherence (22). Hence these uneducated patients should be monitored carefully for treatment adherence by the health care workers. 
Knowledge, perception belief of TB and MDRTB:

Patients' perception of the implication of tuberculosis symptoms, their beliefs and attitudes are potential determinants of compliance ${ }^{(23)}$. The sensation of being cured due to resolution of symptoms, even though treatment has not been completed, has been found to be a common reason for discontinuation of treatment ${ }^{(20)}$.

The present study revealed that only $40 \%$ of MDR-TB knew causes of tuberculosis was some kind of organism, the rest mentioned causes of tuberculosis was smoking, alcohol, hard work, heredity and didn't know. Similarly poor knowledge was observed in the questions related to mode of spread. This result was found similar with the result of study done in Vietnam (24). In the study from Kenya ${ }^{(25)}$, Liefgoohe et al (1997) also found that informants believed their TB was caused by life style and eating habits, drinking "traditional alcohol" and smoking cigarettes as well as sharing facilities with TB patients, findings which are in conformity with the present study. This misunderstanding was thought to be linked to the long time history of tuberculosis in developing countries. It was evident that they still seem to keep traditional ideas on tuberculosis, which reflected in their awareness. In comparison to this, knowledge on duration of treatment, impact of irregular treatment, and curability were satisfactory among study population.

Perception is important factor to change behaviour and implement knowledge in daily life. Studies have shown that higher compliance to TB treatment is associated with patients who knew the TB as the cause of some kind of micro-organism compared to those who mentioned other causes like smoking and alcohol. It is true that who believe TB caused by alcohol, smoking and other cause; they used to focus on avoiding these factors to cure their disease rather than treatment. While preparation of health messages to public, these factors should be considered by the concern authorities.

However, the present study shows different findings in relation to belief in the curability of TB and MDRTB. While many patients in the Kenyan study (25) thought that TB could be cured but not completely, there was general agreement about curability in the present study.

Studies have demonstrated that compliance with anti tuberculosis therapy is enhanced if patients receive an educational programme ${ }^{(26)}$, which is most effective if provided as one to one counselling (27). Hence, adequate counselling and education of patients and close relatives on TB and the necessity for prolonged treatment may play an important role in ensuring completion of treatment.

\section{Quality of Services:}

Quality of services was assessed in terms of waiting time per visit, information given to the patients about TB and MDR-TB and its treatment and side effects, and relationship between patients and health service providers to get high compliance of patients with treatment

Poor behaviour by health care providers towards patients and poor quality of communication between them can affect patients' confidence, leading to treatment non adherence, especially when treatment is prolonged as with TB and MDRTB. In the study from Madagascar (28), it was reported that lack of opportunity to ask questions, insufficient explanation from health workers about disease and treatment, and no information about disease from a doctor were significantly associated with non adherence to TB treatment .In contrast majority of patients and their relatives in the present study were satisfied with the care given by health care workers. Even during holidays (official and unofficial "Bandh") health workers were available in these centres. This is encouraging because earlier studies conducted in Nepal revealed serious breakdowns in the health care worker -patient relationship (Smith 1998)

It is encouraging that more than $90 \%$ of MDR-TB patients stated that they have to wait less than 2 hours to get the services from the treatment centre. Study conducted by Russell mentioned that poor compliance was associated with increased waiting time in the clinic ${ }^{(29)}$. The study revealed that, the Centres in Eastern, Mid and Far Western regions in Nepal had most of the essential resources for the provision of care for MDR-TB patients. In contrast centres in Western and Central regions were lacking certain essential facilities such as drinking water, maintenance of cleanliness and competence of health workers especially giving intra muscular injections.

Infection control is a one of the strategy in preventing TB and MDR-TB. Cleanliness of the clinic is a basic requirement for any health care setting for this purpose. Without adequate and regular supervision, the proper hygienic standard could not be maintained. 
During FGDs many health workers stated that they need protective equipment to prevent against TB and MDR-TB. Studies have shown that health care workers caring for TB patients are at risk for TB infection and disease. Risk is greatest in those HCW with the closest and longest duration of contact with the TB patient. The International Union Against Tuberculosis and Lung Disease and the WHO published a joint statement on the control of TB transmission in healthcare settings. It emphasized the following:

- Early identification of infectious TB patients

- Prompt and effective treatment of such patients

- Isolation of infectious TB patients

- Environmental control with proper ventilation

- Protection of healthcare workers and others

Transmission of TB to HCWs in a public hospital in Brazil was approximately four times greater than the rate in the community ${ }^{(30)}$. In countries like Estonia (31), Turkey (32) Malawi ${ }^{(33),(34)}$ India ${ }^{(35)}$ and Thailand (36) the TB incidences among HCWs were also high, and the quoted risks were 1.5 to 11 fold that in the general population or other comparator groups. Nonexistent or ineffective TB infection control facilitates TB transmission in health care settings. Hence special emphasis should be made by the programme managers in improving these aspects of care in Nepal. This should be accompanied by provision of infrastructure facilities in the clinics such as personal protection equipments, adequate space and ventilation, facilities for hand washing etc.

\section{FINANCIAL BARRIER}

Of the MDR-TB group, almost all indicated that they face problems to attend the clinic in a regular basis. Out of 10 patients in the Far Western region, five $(50 \%)$ stated that they were not attending to the clinic regularly due to financial problems. This percentage in the Eastern and Mid Western region was $30 \%$ and $10 \%$ respectively. This factor is an important public health risk because adherence to daily treatment is the key to successful outcome of MDR-TB .Also untreated sputum positive person can infect 10 to 14 other in a year. Thus, there are important economic and non-economic barriers to treatment adherence which merit attention for both patient and societal benefit. Even though the second line drugs to the patient are given free of charge, the data demonstrate that non -medical costs pose more sizable economic barriers. Thirteen out of 50 MDR-TB patients in the present study stated that their travelling and other costs to attend the clinic were more than 100 NPR (1US\$) per visit. In the context of treating patients with drug sensitive tuberculosis, transportation costs have also been identified in other studies as a significant patient cost ${ }^{(37)}$.

As revealed in Focus Group Discussions it is a disturbing fact that some patients have to sell some of their properties to buy medicine and some have to take out loans, which are frequently offered at exorbitant rates. In Nepal many are under the poverty line. The urban poor are increasing day by day. Most of the TB patients come from the poor society. People cannot afford the travel cost and other expenses from their earnings. In the present study all participants of MDR-TB patients (except mid western region) acknowledged problems, regarding transport costs to obtain treatment, although men were more concerned with the economic burden of treatment. Similarly, studies from Vietnam ${ }^{(4) / 5(8)}$ and Pakistan ${ }^{(7)}$ cite structural barriers such as financial constraints (direct and indirect cost) like loss of income, cost of travel and lodging as the causes of non-adherence to TB treatment.

Incentives are a valuable way to help a person overcome barrier to complete a course of treatment of long duration. In FGD, many patients, Health Workers/ DOTS Committee members/ relatives of patients indicated that financial aid would improve the system. .Many studies conducted in other countries show that modest incentives in a structured programme can produce an effective public health intervention in a typically poor, urban population. There are also other projects where cash and non-cash incentives have improved adherence ${ }^{(38)}$.

Majority of participants in the FGDs thought most MDR-TB patients could not afford the fares to attend treatment clinic, and felt women experience more problems due to lower income. Similar findings were reported in study done by Eastwood and Hill in Gambia. Although many studies have addressed the health provider and drug related costs of tuberculosis, there have been few analyses of the patient-related costs .In rural Uganda and Thailand , respectively, Saunderson and Kamolratanakul et al ${ }^{(39)(40)}$ demonstrated that patients bear more than $60 \%$ of the total burden of tuberculosis costs. The provision of free drug alone is therefore not sufficient. Possible solution to this problem may be to provide accommodation and travel aid for the very poor. 
Focus group discussions revealed many MDRTB patients preferred to attend Central region clinics, because they have more confidence in the Kathmandu health services. Similar findings were reported in the study conducted by Smith 1998 in Nepal. This belief is another factor that leads patients to spend more money for accommodation and other expenses. Even though Nepal government has provided services in all five regions, this message has not reached the public. Like drug sensitive tuberculosis, given the availability of treatment facilities at district clinic, accommodation cost and travel distance may be reduced. These changes are expected to benefit the patient through reduced economic barriers for patients and care givers, including transportation expenditures, accommodation costs, and lost income. A South African study of treatment strategies has also demonstrated the significant economic benefit to patients of using nearby clinics for drug distribution ${ }^{(37)}$.These benefits to patients must, however, be weighed against other risks and benefits of decentralization before a decision can be made regarding the ultimate impact on tuberculosis control.

Cured TB patients and health workers acknowledged that the use of unqualified private practitioners before government medical services was wide spread and this is the main reasons for MDR-TB in Nepal. Few MDR-TB patients stated that they had used traditional healers previously. Motivation for using traditional medicine varied but many patients claimed to have done so because of easy access, confidentiality, local availability and on the advice of others. Quality of care has been found to be an important determinant in patients choice of health facility and can lead to by passing free public health facilities in spite of free paying services in some settings. ${ }^{(41)}$ It is encouraging that, majority of MDR-TB patients in the present study believe that government treatment for MDR-TB is much better than private sector treatment including traditional healers. The importance of staff, community, motivation and a feeling of ownership of the programme in the success of the DOTS strategy in Nepal has recently been highlighted ${ }^{(42)}$.

During FGDs majority of DOTS Committee members, cured TB patients suggested that health care workers should intensively supervise patients because they may be discontinuing treatment. The first response of HCW s in Nepal, when asked about how to address the problems of non adherence, they often stated that a tracing system needs to be initiated. This is important because non adherence of MDR-TB patients can spread their disease to normal population.

\section{SOCIAL STIGMA AND DICREIMINATION}

Findings of FGDs revealed very little stigma and discrimination associated with TB and MDR-TB patients among health workers, family members and friends of the patients. But few TB patients mentioned cases of landlords evicting these patients and several patients were hiding their diagnosis from their landlords and outsiders. The stigma associated with TB might well be another reason why many Nepalese travel so extensively when they seek medical care. Many important points that came up in the FGD concerned treatment seeking behaviours of women. Female patients were more bothered than male patients about the lack of privacy in the clinic. Nearly half of the female MDR-TB patients interviewed stated that they would prefer a female health worker to deliver their treatment.

\section{LIMITATION}

Care should be taken before generalizing these findings, due to the small number of cases interviewed in the study and qualitative nature of the study. Non randomized sampling method may also have introduced hidden biases even though it is common in all qualitative studies. Finally, the reasons stated for barriers by the study participants have been taken as a statement of fact. This, however, cannot be validated and must be accepted as a limitation of the study finding. Despite the above considerations, the present study highlights areas for concern that require action to further improvement in MDR-TB treatment in Nepal.

\section{CONFLICT OF INTEREST}

None

\section{REFERENCES}

1. Epidemiological Update SAARC TB and HIVIAIDS Centre, 2017

2. WHO (2003). Adherence to long term therapies: evidence for action. Geneva, Switzerland

3. Sackett et al (1991). Clinical epidemiology: a basic science for clinical medicine. Second edition . Lippincott Williams and Wilkins. USA, 249-81

4. Johansson $\mathrm{E}$ et al. Staff and patient attitudes to TB and compliance with treatment; an exploratory study in a district in Vietnam. Tubercle and Lung Disease 1996; 77: 178-83 
5. Long $\mathrm{NH}$ et al. Fear and social isolation as consequences of TB in Vietnam; a gender analysis. Health Policy 2001; 58: 69-81

6. Jaiswal A et al. Adherence to TB treatment: lessons from the urban setting of Delhi, India. Topical Medicine and International Health 2003; 8; 625-33

7. Khan $A$ et al. TB in Pakistan: socio- cultural constraints and opportunities in treatment. Social Sciences and Medicine 2000; 50: 247-54

8. Johansson $E$ et al. Attitude to compliance with TB treatment among women and men in Vietnam. International Journal of TB and Lung disease 1999; $3: 862-8$

9. Thorson A et al. Gender inequalities in tuberculosis; aspect of infection, notification rates, and compliance. Current Opinion in Pulmonary Medicine 2001; 7: 165-9

10. Patton MQ (1990). Qualitative evaluation and research methods. $2^{\text {nd }}$ ed. Newbury Park: sage Publication.

11. Hudelson P. Qualitative Research for Health Programmes. Geneva: Division of Mental Health, World Health Organization; 1994.

12. World Health Organization(1993) A Practical Guide for Researchers and Activists; Developing a Sampling Strategy pp-105-14

13. Spence DP,Hotchkiss J, Williams CS,Davies PD. Tuberculosis and poverty.BMJ 1993;307:759-761

14. Sidel VW,Drucker E, Martin SC. The resurgence of tuberculosis in the United States: societal origins and societal responses. J Law Med Ethics 1993;21:303-316

15. Nair DM,George A,Chacko KT. Tuberculosis in Bombay: new insights from poor urban patients. Health Policy and Planning 1997; 12:77-85.

16. Barnhoorn $F$, Adriaanse $H$. In search of factors responsible for non compliance among tuberculosis patients in Wardha District, India. Soc Sci Med 1992;34:291-306.

17. Rubel AJ, Garro LC. Social and cultural factors in the successful control of tuberculosis. Public Health REP 1992;107:626-636

18. Sumartojo $E$. When tuberculosis treatment fails. A social behavioural account of patients adherence. Am Rev. Respir Dis 1993;147:1311-1320.

19. Sockrider $M M$, Wolle $J$ M.Helping patients better adhere to treatment regimen. J Respir Dis 1996;17:204-216.
20. Mori T, Shimao T, Jin BW, Kim SJ. Analysis of case finding process of tuberculosis in Korea. Tubercle Lung Dis 1992;73:225-231.

21. Smith I .TB Do or Die : Journalists take a close look at how Asian countries are fighting tuberculosis. 1998.

22. Demissie M, Kebeda D (1994). Defaulting from TB treatment at the Addis Abeba TB centre and factor associated with it. Ethiopian Medical Journal , 32, 97-106.

23. Haynes RB,A critical review of the 'determinants' of patients compliance with therapeutic regimens. In:Haynes RB, Taylor DW, Sackett DL, eds, Compliance in health care. Baltimore:John Hopkins University Press 1979:26-39

24. Johansson E, Long NH, Diwan VK, Winkvist A (1999). Attitudes to compliance with tuberculosis treatment among women and men in Vietnam. International Journal of Tuberculosis and Lung Disease, 3, 862,8.

25. Liefooghe $\mathrm{R}$, Michiels $\mathrm{N}$, Habib S, Moran MB De Muynck A (1997). From their own perspective: a Kenyan community's perception of tuberculosis. Tropical Medicine and International Health, 2, 80921.

26. Morisky D E,Malotte C K,Choi P et al. A patient education programme to improve adherence rates with anti tuberculosis drug regimes. Health Educ $Q$ 1990;17:253-267.

27. Cuneo W, snider D E. Enhancing patients compliance with tuberculosis therapy. Clin Chest Med 1989;3:375-379.

28. Comlet $T M$, Rakotomalala $\mathrm{R}$, Rajaonarioa $\mathrm{H}$ (1998). Factors determining compliance with tuberculosis treatment in an urban environment, Tamatave, Madagascar. International Journal of Tuberculosis and Lung Disease, 2, 891-7

29. Russell ML. Behavioural counselling in medicine; stratergies for modifying at -risk behavior. OXFORD University Press, New York 1986.

30. Cuhadaroglu C, Ercelel M. Tabak L. Kilicastan Z. Increased risk of tuberculosis in health care workers; a retrospective survey at a teaching hospital in Istanbul, Turkey, BMC infect Dis 2002;2:14

31. Kruuner A. Danilovitsh M, Pehme L, Laisaar T, Hoffner SE, Katila ML. Tuberculosis as an occupational hazard for health care workers in Estonia. Int J Tuberc Lung Dis 2001; 5:170-6

32. Kilinc O, Ucan ES, Cakan MD, et al. Risk of tuberculosis among healthcare workers: can 
tuberculosis be considered as an occupational disease? Respir Med 2002; 96:506-10.

33. Harries AD, Nyirenda TE, Banerjee A. Boeree MJ. Salaniponi FM Tuberculosis in health care workers in Malawi, Trans R Soc Trop Med Hyg 1999,93:325

34. Kanyerere HS. Salaniponi FM Tuberculosis in health care workers in a central hospital in Malawi. Int J Tuberc Lung Dis 2004;8:1392-4

35. Rao KG, Aggarwal AN, Behera D. Tuberculosis among physicians in trainign Int $\mathrm{J}$ Tuberc Lung Dis 2004:8:1392-4

36. JiamjarasrangsiW, HirunsuthikulN, Kamolratanakul P. Tuberculosis among health care workers at king chulalongkorn Memorial Hospital, 1988-2002. Int J tuberc Lung Dis 2005;9:1253-8

37. Wilkinson D,Floyd K,Gilks C F. Costs and cost-effectiveness of alternative tuberculosis management strategies in South Africa-implication for policy. S Afr Med J 1997;87:451-455
38. Kissinger $P$ et al . The effects of modest monetary incentives on follow up rates in STI studies. It $\mathrm{J}$ STDAIDS 2000,11:27-30.

39. Saunderson PR.An economic evaluation of alternative programme designs for tuberculosis control in rural Uganda.Soc Sci Med 1995;40:12031212.

40. Kamolratanakul P,Chunhaswasdikul B, Jittinandana A, et al. Cost effectiveness analysis of three short course anti tuberculosis programmes compared with a standard regimen in Thailand. J Clin Epidemimol 1993;46:631-636.

41. Akin J.S,Hutchinson P. Health care facility chice and the phenomenon of by passing . Health Policy Planning 1999;14:135-151..

42. Wares D.F., Akthar M, Singh S. DOT for patient with limited access to health care facilities in a hill districts of Eastern Nepal. Int J, Tubercle and Lung Disease 2001;5:732-740. 